\title{
The Listen-to-write Approach Proposed for EFL Teachers of College English in China: Definition and Its Essentials
}

\author{
Qingsong $\mathrm{Gu}$ \\ Shanghai University of Engineering Science, Shanghai, China
}

\begin{abstract}
College English writing in China has been faced with at least three problems: marginalization, poor input and reducing participation of the teacher. Considering these problems, the author introduced listening in the teaching of College English writing and this strategy has developed into an integrated approach: The Listen-to-Write Approach. In this paper, the author gives a complete and comprehensive definition to the Approach and has a detailed study of its essentials, including EFL classroom teaching, the intensification of listening, the assistance by computer technology, and the orientation to classroom teaching as a cognitive process. Finally, the author presents an overview of the Approach by analyzing its strengths and weaknesses, which helps readers to make their own decisions on it.
\end{abstract}

Index Terms - College English writing, EFL, listening, cognitive processes, classroom teaching

\section{INTRODUCTION}

\section{A. Problems in the Teaching of College English Writing in China}

It is indisputable that the teaching of College English writing in China has been marginalized to a great extent. From the design of syllabus, the system of credits, and the development of testing, it is hard to see any advantages of writing over speaking, listening or reading. In 2007, the Chinese Education Department advocated communicative language teaching (CLT), aiming to raise learners' English level significantly, especially in listening and speaking, in the context of study, work and social interaction (Cai, 2014). Unfortunately, we saw very little emphasis on writing. Even worse, English writing courses are mostly designed and opened to English majors while non-English majors, occupying the overwhelming majority of college students in China, learn English writing only through intensive reading courses, where English writing is neglected as a kind of dispensable homework, or through a limited number of selective courses on English writing.

Actually, the marginalization of teaching English writing in China has led directly to a serious problem of poor input. The input, which involves language knowledge and language competence, is poor both at quality in terms of accuracy and authenticity and at quantity in terms of time and practice. For a long time English teaching in China has been criticized for producing low output with high input (Luo, J. \& Garner, M., 2017). It sounds right in some sense from the perspective of time and economy. It is often the case in China that large amounts of time and money have been spent over ten years or more for a single person to learn English from elementary school to higher education, but may end up with an English learner who is able to read and write but whose oral and aural skills are insufficient. However, from the perspective of language teaching, that is not so simple. First, "high input" is a bit ambiguous. At least in current English teaching this very "high input" does not necessarily equate to the high-quality input that is accurate and adequate. Second, "low output" is considerably confined to the poor ability of speaking because, when it comes to the judgement of a person's language competence by output, emphasis tends to be placed on speaking rather than writing.

The third problem in teaching English writing in China is the reducing participation of the teacher. The shift of classroom roles from the teacher to students has been an anti-tradition practice strongly recommended in College English teaching. Student-centered teaching may be effective for speaking classes since output practices really help develop speaking ability. But in writing classes, excessive attention paid to students' output at the cost of inadequate input certainly results in poor output. It is clear that the reduction of the teacher's participation has unconsciously become a problem in the teaching of English writing in China. Traditionally, the teacher of English writing designs all the contents of classroom teaching, leaving necessary and appropriate time for drills, practice and feedback. This traditional way helps intensify the input in the classroom teaching. But now students are given too much freedom both inside and outside the classroom, which may do harm to the accuracy of input. For example, they are sometimes encouraged to learn from each other by reading the writing samples of their partners. This is not so much learning strengths from each other as developing a sense of making similar mistakes made by their partners because in most of their writing samples drawbacks outweigh merits. Another example is plagiarism. Students usually finish their writing assignments after class by simply copying the writing materials from the internet. This freedom may greatly constrain their ability of thinking and creating because, unconsciously, they are getting too much dependent on online resources 
for writing.

\section{B. Deliberations on Solving These Problems}

Marginalization, poor input and the reduction of the teacher's participation have long existed as the main problems in the teaching of College English writing in China, but it is not an easy thing to make a sudden change or profound improvement because it needs multi-efforts from learners, the teacher and the nation.

In recent years, English for Specific Purposes (ESP) has become a good choice and an important part of English teaching in some universities in China. Many English writing courses related to business, biology, engineering, nursing, and other special purposes are designed for undergraduates, who can learn to write with interest and motivation in their specific discipline after they complete College English. It seems to be a promising sign, but the key to improving English writing ability is not only with the favorable atmosphere created by the nation; the use made of the good intentions and policies of the nation may be limited and uncertain. The key is not only with the interest or motivation of learners; most learners are always ready to learn. It is, from my own point of view, the efficient and effective input in classroom teaching that really counts in the teaching of College English writing in China.

Taking steps along this path, I did some research and accumulated many teaching experiences. In the end, I decided to apply listening in the classroom teaching of English writing and this has developed into an integrated approach: the Listen-to-Write Approach (LWA).

\section{DEFINITION}

In A Theoretical and Practical Study of the Listen-to-Write Approach (Gu, 2014), I offered the first complete and most comprehensive definition of LWA in Chinese. The following is its English version with minor editions.

LWA is a listening-intensified, computer-assisted and process-oriented approach proposed for EFL teachers of College English in China to improve students' English writing ability in a SLA classroom environment. In LWA, the teacher arranges the class as a cognitive process integrated with task-based activities, exposing students to sorted, step-by-step and repeated listening to writing-related language materials which are selected from authentic, native and formal written documents and recorded as audio files by humans or speech recognition software with purposeful editions. Meanwhile, the teacher engages them in writing practices as a reinforcement, in an attempt for them to accumulate the language information for writing, to transform as much the information as possible from short-term memory to long-term memory, and hence to have the ability of outputing the information they have obtained as long-term memory whenever it is needed in writing practices.

\section{ESSENTIALS OF THE DEFINITION}

\section{A. EFL Classroom Teaching}

EFL classroom teaching, as oppose to ESL classroom teaching, is the essence of LWA. It involves the following three aspects: EFL, classroom, and teaching. Each is discussed in greater detail blow.

First, LWA defines its teaching environment as an EFL classroom in China, where English is being taught as a foreign language for the students who share the same Chinese language and culture. As we all know, teaching English as a second language (TESL) is different from teaching English as a foreign language (TEFL). ESL classes typically take place in an English-speaking country with students from different backgrounds and with different home languages, while EFL classes are conducted in a non-English speaking country with students from the same country and with the same home or national language. The ESL classroom is a heterogeneous context while the EFL classroom is for all intents and purposes a homogeneous context. Now that LWA is applied in China, it is simply characterized by EFL. It is true that TESL may have greater advantages over TEFL for English learners, but TEFL at least has one advantage which seems to lie in the fact that EFL learners can easily communicate with each other, and interestingly in the fact that they usually make the same mistakes which may be comparatively easy for the teacher to correct or make comments on. Fortunately, this advantage of TEFL may be taken in LWA to achieve high efficiency in the teaching of English writing.

Second, the teaching of English writing in LWA is conducted in the classroom rather than out of the classroom. ESL learners have the opportunity for extensive daily exposure to the English language and culture if they choose to engage with the host language and culture, so after class they have many opportunities to acquire language skills in an authentic English-speaking environment. On the contrary, EFL learners have much less exposure to the English language and culture and they have very few opportunities to use English in authentic and real-life interactions outside classroom. In consideration of the lack of access to English in a TEFL context, LWA restricts activities to the classroom for the purpose of making good use of the controlled classroom teaching environment.

Third, the dominant role in LWA is the teacher rather than the learners, or more exactly, LWA focuses more on how to teach than on how to learn. All the Listen-to-Write activities are similar to film making. The teacher is the director and gives orders; learners are actors or actresses who follow these orders. It is not that learning activities are negligible but that they are instructed and dominated by the teacher. LWA advocates teacher-centered teaching primarily to guarantee the quality and quantity of input, which I believe are integral in improving writing ability.

\section{B. The Intensification of Listening}


Language skills are often categorized as receptive or productive (Nunan, 2003). Listening and reading are receptive skills and serve as a kind of input for students studying and learning an additional language. Likewise, speaking and writing are productive skills serving as conduits for language output. In language acquisition, the four skills are correlated to some extent. The language competence acquired from one skill may be the foundation of another skill. It is common sense that reading improves writing. Du Fu, a famous Chinese poet in the Tang Dynasty, said, "only through reading thousands of books can one write well (读书破万卷, 下笔如有神)”. Reading, as an input skill, has been traditionally thought of as the most effective way to improve writing. Then, how about listening, the other input skill? Is there any positive correlation between listening and writing? How does listening improve writing? Why is listening used to improve writing in a Listen-to-Write class?

In first-language acquisition, there are actually two main guiding principles: 1) speech perception always precedes speech production and 2) the gradually evolving system by which a child learns a language is built up one step at a time, beginning with the distinction between individual phonemes (Fry, 1977). Speech sound perception and production form the basis for speaking. From birth, or even earlier, infants are exposed to repeated listening to the native speech sounds before they suddenly start to speak. No matter how many debates there have been on infants' language acquisition, it is no doubt that listening plays a decisive role.

Then, can we borrow the process (or principles) of listening in first-language acquisition in the teaching of writing in an EFL/ESL context? We certainly can, not simply because the input through listening is beneficial to the output in speaking and writing, but because listening, especially repeated and intensified listening, greatly helps transform the language input from short-term memory to long-term memory which has the potential to greatly improve writing skills.

Memory can be understood as an organism's ability to store, retain, and recall information. In the eyes of psychologists, memory comprises sensory memory, short-term memory, and long-term memory in terms of its span (Gui, 2000). Andy Hudmon (2006) describes that long-term memory, unlike sensory and short-term memories, is able to retain information over extended periods of time (minutes, hours, or a lifetime) and can transfer information out of short-term (working) memory into a more stable medium that is less sensitive to interference or disturbance (i.e., from incoming sensory information). While a person is writing, information is being actively taken out of long term memory and purposefully processed which in turn adds additional exemplars to the long term memory. Writing is a process of outputting information in an accurate way, so it may depend more on long-term memory than on short-term memory. Traditionally, reading is accepted as the main supporting skill for writing, and listening as the main supporting skill for speaking. But actually, listening contributes not only to comprehension but also to memory, and, therefore, it can and does support writing.

It was in 1992 when I first came across the idea about the relation between listening and writing in the preface to the book How to Improve CET Writing (Gu, 1992), where Professor Mingfang Wu pointed out, "Listening is also a good way to improve the ability of writing". In 2006, this idea was reinforced by a personal experience in Nantong University. It was the time for final exams. I invigilated an English exam with one of my colleagues. A student handed in his paper exceptionally early. I had a glance at his paper out of curiosity, only to find a long Chinese poem written in the area for English writing. It is often the case in China that poor students hand in their test papers very early and write or draw something for fun. I was very much touched by the content of the whole poem and could hardly wait to share it with my colleague. To my great surprise, my colleague showed very little notice of my excitement, saying, "Nothing special. Just a copy of some lines of lyrics from A Thousand Miles Away (《千里之外》)”. At that moment, I was a little embarrassed because I didn't know that the "poem" by the student came from the song, even though it was then very popular all over the country. But fortunately, I learned something from the experience - writing is closely related to listening. The student was probably not a poet at all, but the fact that he wrote so many lines on the paper reflected his ability for "writing" to some degree. Did he output so much information on his testing paper just because he had got himself familiar with the lyrics of the song by reading them many times? Not really. It was repeated listening and active imitating that helped him learn how to sing the song and memorize the lyrics. What if the writing of the paper was coincidentally related to the song? The student would have a lot to write, but I couldn't. As the famous Chinese saying goes, “a layman in poetry could easily utter a poem after he had recited 300 poems in the Tang Dynasty (熟读唐诗三百

\section{首, 不会吟诗也会吟)”.}

In LWA, listening is intensified for at least three reasons. First, intensified listening can be well designed in a Listen-to-Write class to amplify the input of language information in quantity and improve its accuracy and authenticity. In addition, some of the input information can be easily transformed to long-term memory through repeated listening. Finally, it is much easier for the teacher to manipulate listening in a Listen-to-Write class because all the listening activities are prepared by the teacher and carried out in the classroom rather than out of the classroom.

\section{The Assistance by Computer Technology}

Computer technology is widely applied in LWA to maximize the benefits of listening for improving the ability of writing. Computer-assisted language learning (CALL) emphasizes student-centered classes where students are encouraged to learn independently through using structured and/or unstructured interactive exercises, while in the Listen-to-Write classes, computer-assisted language teaching (CALT, which I borrow from CALL) plays a dominant 
role, underlining teacher-centered classroom teaching through exposing students to intensified listening. The computer technology used in LWA includes language labs, the Internet and audio editing softwares.

First, language labs are recommended in LWA to guarantee the quality of listening and the effect of teaching. In a language lab, the teacher can easily control the digital system connected to a number of student booths. There is less miscommunication than in regular classroom teaching because of direct nature of the sound transmission. More importantly, in a language lab, students show more enthusiasm in learning and are more willing to record and check their own voices with very few distractions from others.

Second, the Internet is used in LWA as a good source of listening materials, which are usually prepared by the teacher for a certain task. The Internet can also be used as a platform for checking homework or testing students' writing ability. Most important of all, the use of corpora and concordances in the Internet serves as a great help for the teacher to check the accuracy and authenticity of lexical language materials. For example, if the teacher wants to decide which is correct, "as a saying goes" or "as the saying goes", he may easily get the answer from The Corpus of Contemporary American English (COCA). When "as a saying goes" is searched, it says "ERROR". But, when "as the saying goes" is searched, its frequency is 227 and its context is rich in details (See Figure 1).

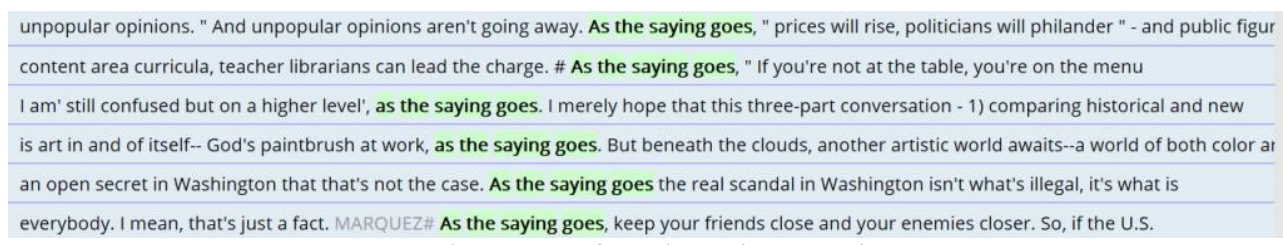

Third, anyone of the audio editing software, such as Audacity, Adobe Audition, CoolEdit and GoldWave, can be used in LWA to enhance the effect of memorizing language information that is needed for writing. With the use of audio editing softwares, the teacher can not only edit the sound files recorded by human or software for the tasks to be conducted in the classroom teaching, he can also play the edited files freely to meet the needs of classroom teaching. It is not easy to use a tape recorder to replay the exact language units, but with the help of an audio editing software, words, expressions, sentences, and paragraphs can be played accurately and repeatedly. For example, "phenomenon" is a frequently-used word in English writing, but it is difficult to spell. In LWA, each recording of "phenomenon" can be split into four syllables (phe-no-me-non) and edited with different intervals. Usually, five recordings of "phenomenon" with intervals are played repeatedly together with another five without intervals (See Figure 2).

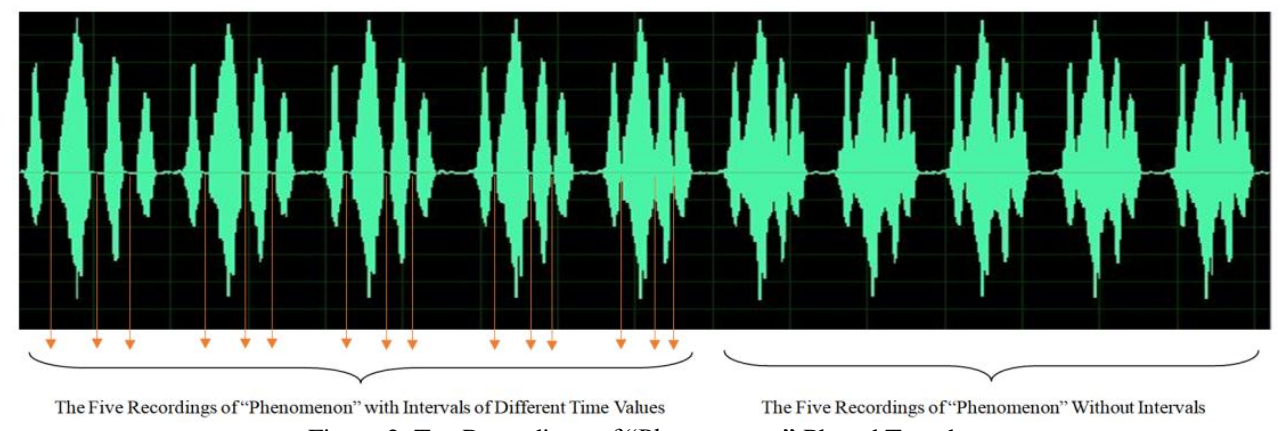

Figure 2. Ten Recordings of "Phenomenon" Played Together

Another example is the intensive listening to a selected part of a sentence or paragraph. All audio editing softwares have the function of automatic replay (See Figure 3) which can be used to intensify listening through repetition.

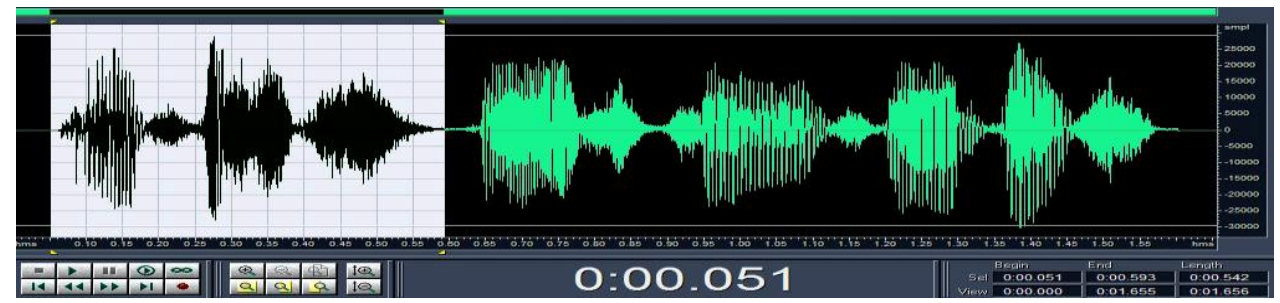

Figure 3. Intensify Listening Through Repetition

\section{The Orientation to Classroom Teaching as a Cognitive Process}

To develop the ability of English writing is the final target of LWA. Listening seems to be a complementary teaching strategy, but it is applied throughout the whole process of classroom teaching, so the Liten-to-Write classes are featured with the characteristics of listening classes. However, a Listen-to-Write class is not a simple combination of listening 
and writing, but a cognitive process which is well designed and arranged by the teacher and integrated with some task-based activities.

Cognition is a mental process of knowing and understanding. Cognitive processes use existing knowledge and generate new knowledge. A cognitive process may have several stages (See Figure 4).

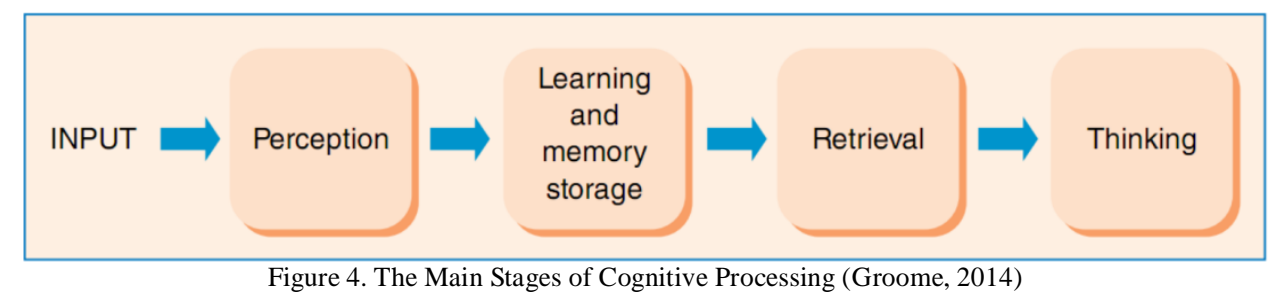

Studies on cognition tend to start with listening probably because listening stimulates the brain more than other skills and it does play a crucial role in L1 acquisition. Much of our current understanding of how individuals process spoken signals and construct meaning from them has been illuminated by theoretical perspectives from cognitive psychology (Celce-Murcia, M., Brinton, M. D. \& Snow, A. M., 2014). The function of cognitive processes during listening can be explained by the three recurrent and overlapping phases - perception, parsing, and utilization (Anderson, 1995), which very well match the main stages suggested by David Groome (2014).

In LWA, the cognitive processes of listening are sure to be influenced by writing activities. For example, when a writing task is introduced, the listening process is broken up and some cognitive stages, say Retrieval and Thinking, may be transferred to the writing process. Fortunately, listening doesn't conflict with writing in LWA; by contrast, it serves as a competent catalyst and a good coordinator. Moreover, Top-Down and Bottom-Up, the two main types of input processing identified by Neisser (1967), can be shared by listening and writing, as is to be discussed subsequently. However, it is worth mentioning that the listening applied in LWA differs from the listening in a regular listening class in that the former focuses on how much language information can be transformed to long-term memory with the help of intensified listening, whereas the latter focuses on how well listening skills are developed and used for the listener to communicate with the speaker. Accordingly, listening activities like "Top-Down to Bottom-Up" and "Input for Output" are usually designed on a task basis in LWA to meet the needs of improving the ability of writing.

\section{E. Classroom Activities}

In LWA, listening is purposefully intensified through well-designed and task-based activities in an effort to achieve high-quality input in an effective and efficient way, which serves as a great help to the output in writing activities. Basically, there are five types of activities which are recommendable for a Listen-to-Write class: Listen-Write, Guess-Listen-Write, Translate-Listen-Write, Think-Listen-Write and Write-Listen-Write, which are demonstrated in detail in the following examples.

1) Listen-Write

Directions: In this section, you are asked to read aloud after the speaker and write down what you hear.

1.

2 .

3.

4.

5 .

(See the keys in Appendix 1 for reference)

Listen-Write is often used as a warming-up practice for the students to get familiar with the important words or phrases selected from a well-written essay which has been prepared purposefully as a sample writing and is to be studied throughout the Listen-to-Write class. This task is similar to dictation, but it is more than that because the students are asked to read aloud after the speaker, aiming to input language information via sounds. In some sense, Listen-Write is a very simple Bottom-Up process.

2) Guess-Listen-Write

Directions: In this section, you are first asked to guess whatever goes in each blank. Then, listen to each item, and fill in the blanks with what you hear. Finally, check what you have written with what you have guessed.

1. The of living in a new environment can give you courage and self-confidence.

2. If you are thinking about where to study, consider all of these benefits and make a decision that is for you.

......

(See the keys in Appendix 2 for reference)

Guess-Listen-Write encourages the participation of the students. It seems to be a Top-Down processing, but actually it is a Bottom-Up processing because students are stimulated to know and understand in a cognitive process.

Guess-Listen-Write is often used for paragraphs in the form of Gap-Filling. The selected paragraph shall be a good sample of writing and gaps to be filled include connectives (e.g., conversely, as a result, after all, what's more, in a 
word), often-used writing expressions (e.g., contribute to, arise from, take effective measures), and any recommendable writing expressions (e.g., just as a coin has two sides, it goes without saying that, it is interpreted to mean that). The following Gap-Filling practice helps the students to know and understand the often-used expressions in a writing of comparison.

Working in the office and working from home have advantages. In the office, you will have much contact with your colleagues. Daily contact with people at work is often how good friendships are made.

it can be very easy to concentrate on work in the office because there are very few opportunities to do private things. the working atmosphere helps one work enthusiastically and efficiently.

there are also advantages of working from home. you do not have to commute to work. Millions of people worldwide have to deal with rush-hour traffic to make their way to the office. , this is not necessary if you turn your home into your place of work , working at home gives you much more freedom to manage your working day. and your timetable is decided for you.
if working in the office costs a lot, working from home will be the best replacement (See the keys in Appendix 3 for , if you work in an office, you are often asked to attend meetings, reference).

3) Translate-Listen-Write

Directions: In this section, you are first asked to translate each item into English. Then, listen to its English version carefully, and write down what you hear. Each item will be read twice. Finally, check what you have written with what you have translated.

1. 生活在国外会是一次令人激动的经历, 因为一切看起来都很新奇。

Translation:

Dictation:

2. 生活在国外的另一个理由是可以更好地了解异域文化。

Translation:

Dictation:

3. 然而, 在国内学习也有一些优势。

Translation:

Dictation:

4. 在国内, 你不必担心上课讲的都是外语。

Translation:

Dictation:

5. 如果呆在国内, 你的家和朋友都会离你很近。

Translation:

Dictation:

(See the keys in Appendix 4 for reference)

It is often the case that in the process of writing an English essay, most EFL students are doing translation work, so LWA applies translating in classroom teaching. In Figure 5, translating is an indispensable part in the "Cognitive Process Theory of Writing (Flower and Hayes Model)". 


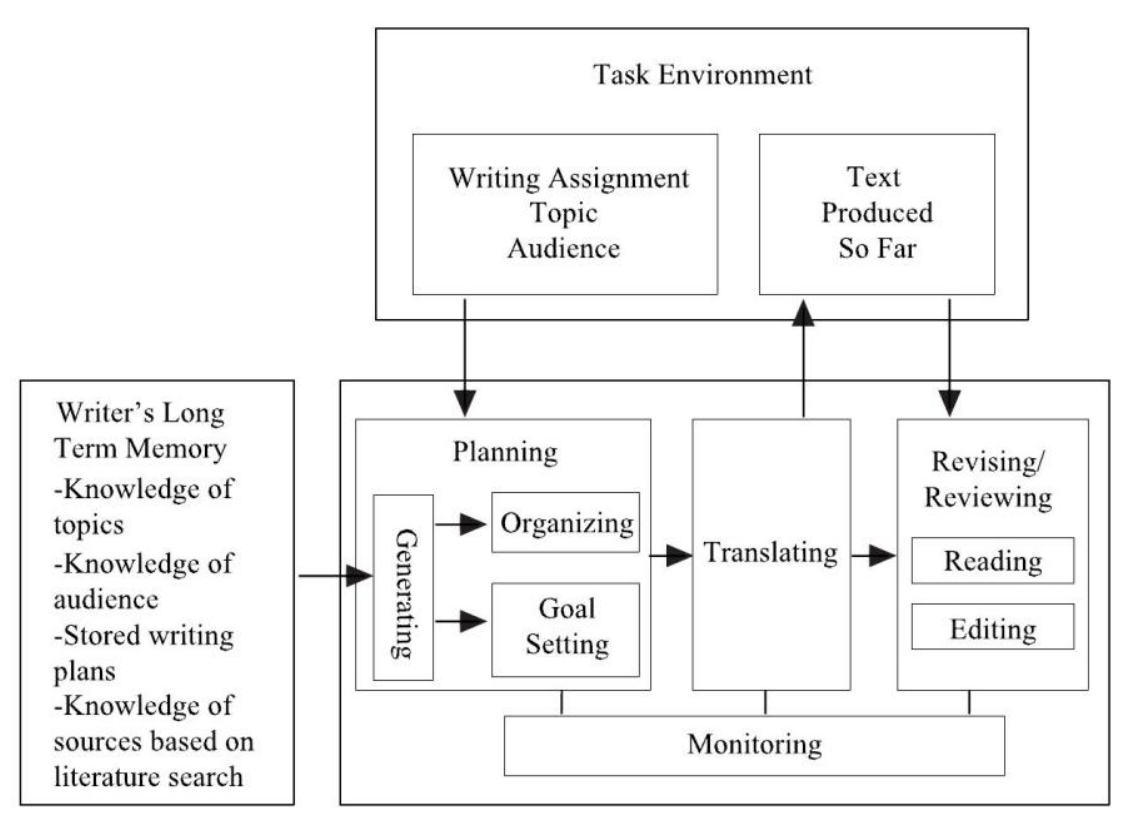

Figure 5. Cognitive Process Theory of Writing (Flower and Hayes Model) (Flower, L. \& Hayes, J. R., 1981)

As an effective activity in LWA, Translate-Listen-Write is often recommended for sentences. This doesn't mislead students to use much translation in writing, but helps them to effectively know and understand sentence patterns, especially those featured with coordinators (and, but, or and so) or subordinators (because, if, although, etc.).

4) Think-Listen-Write

Directions: Please think about three advantages of both online shopping and in-store shopping. Then, write down what you hear.

Online Shopping

1.

2.

3.

In-store Shopping

1 .

2 .

3.

(See the keys in Appendix 5 for reference)

Think-Listen-Write differs from Guess-Listen-Write. Thinking is much less casual than guessing. Students make more use of their schematic knowledge while they are thinking, so Think-Listen-Write can be treated as a Top-Down processing.

5) Write-Listen-Write

Directions: In this section, you are first asked to write a paragraph about the advantages of both studying abroad and studying in your own country. Then, listen to the sample paragraph intensively and write down on your notebook whatever you hear (See the keys in Appendix 6 for reference).

Write-Listen-Write is often conducted in the end of a Listen-to-Write class and shall be closely related to the input from previous activities. For example, the topic "The Advantages of Working from Home and Working in the Office" (demonstrated in Guess-Listen-Write previously), the topic "Online shopping and In-store Shopping" (demonstrated in Think-Listen-Write previously), and the topic in this task are intentionally put together in the same Listen-to-Write class to help students to learn how to write a paragraph of comparison through an input-based output.

In The Listen-to-Write Approach to Improving CET Writing (Gu, 2016), the above five classroom activities are often carried out step by step as an integrity, as is shown in Table 1.

TABLE 1.

THE FIVE ClASSROOM ACTIVITIES CARRIED OUT AS AN INTEGRITY

\begin{tabular}{llll}
\hline Step & Classroom Activity & Language Level & Cognitive Process \\
\hline 1) & Listen-Write & Word & Input \\
2) & Guess-Listen-Write & Word / Phrase & Input \\
$3)$ & Translate-Listen-Write & Sentence & Output $\rightarrow$ Input \\
$4)$ & Think-Listen-Write & Sentence / Paragraph & Output $\rightarrow$ Input \\
5) & Write-Listen-Write & Paragraph / Text & Output $\rightarrow$ Input \\
\hline
\end{tabular}

From the table we can see that the language levels for classroom activities are changing gradually from a low one to a higher one and that students are placed in a cognitive process of learning how to write through alternating sequence of 
input and output activities.

More importantly, all the activities in the class center around the final target - students end up with a fine memorization of a purposefully-selected sample writing ( either paragraph or essay) and a general knowledge of how to write in the same way as the sample. As can be seen from the following appendixes, the language points in each step are highly related to the final target - memorize a sample of writing about studying abroad and learn how to write a paragraph of comparison on any topics.

It is worth mentioning that the paragraph in Guess-Listen-Write originates from IELTS Advantage Writing Skills (Brown, R. \& Richards, L., 2011). The original sample of writing is about how to demonstrate advantages and disadvantages, but the task in Write-Listen-Write is to compare only advantages, so many purposeful editions have been made to the selected materials from the original sample.

\section{StRENGTHS AND WeaknesSes}

The use of listening in the teaching of English writing may not be a new thing, but to define LWA as a TEFL approach in China is “the first time to eat crabs (第一次吃蜳蟹)". Just as a coin has two sides, LWA has both strengths and weaknesses.

\section{A. Strengths}

First, the classroom teaching of English writing in LWA is more productive and controllable than the teaching out of the classroom. The students and the teacher are working in an EFL environment, sharing the same language and culture, so they have hardly any difficulties in communicating and understanding, which greatly helps raise the efficiency of teaching and create a relaxed atmosphere of thinking. Interestingly, students think in a similar way and usually make the same mistakes which can be more easily identified and corrected by the teacher.

Second, the intensification of listening in LWA helps students to acquire language and skills in a virtue but similar environment of L1 acquisition, where students may achieve better results of learning through constant listening. Also, students tend to enjoy the process of listening to the formal written materials which they normally get to know and understand by hard and boring reading.

Third, the use of advanced computer technology is a big advantage in LWA. With the help of computer technology, the teacher can have free and best choices from the vast pool of language materials for English writing and record them as high-quality audio files. Also, correcting mistakes will be much easier when the Internet is used.

Fourth, the application of LWA is transferable from China to any other non-English speaking nations, where students are also taught in an EFL environment. Although the status quo of teaching English writing in China may be quite different from that of other nations, the actual fact is that the more and better input of language information students accumulate, either through listening or reading, the more they will benefit to improve their output, either in the form of speaking or writing.

\section{B. Weaknesses}

First, the classroom teaching in LWA depends too much on the teacher's pre-class preparation and while-class arrangement. A single mistake or any carelessness of the teacher may probably bring about improper selection of materials, unbearable quality of recordings, questionable design of task-based activities, and poor arrangement of the class. The teacher is required to develop other abilities beyond that of language teaching, such as the know-how of computer science, the familiarity with the popular audio technology, and the operation of multi-media devices.

Second, excessive exposure to listening may easily make students loose their patience. My teaching experiences show that few students can concentrate on listening for more than half an hour in a Listen-to-Write class. Impatience is a big challenge to efficiency.

Third, the requirements for the textbook in LWA are very high. In the textbook, there should be adequate language information, a great many good writing samples and a variety of task-based activities. Also, all the audio files need to be made professionally from native English speakers.

Fourth, the ways to assess LWA are still uncertain. Listening needs patience and persistence, so does writing. Students often feel frustrated at the first few weeks of the Listen-to-Write practice because they notice almost no obvious improvements. At the crucial Listen-to-Write stages, students need inspiration and encouragement from the teacher to build up their confidence.

\section{SUMMARIZATION}

The highlight of LWA is the application of listening in the teaching of College English writing in the classroom. It is specially designed for EFL teachers in China. While it is true that the intensification of listening does improve writing through converting language information from short-term memory to long-term memory, it cannot be said that listening is versatile in LWA. Listening needs patience and the listening in LWA needs far more patience, so LWA will surely be a big challenge to both the teacher and students. 


\section{ACKNOWLEDGEMENTS}

First, this paper is fully indebted to the support from the 2017 Overseas Research Scholar Program for Young and Middle-aged Teachers of Higher Education in Shanghai, which was sponsored by Shanghai Municipal Education Commission. Second, this paper was supported by College English Listening (s201718001), one of the 2017 Key-curriculum Construction Projects for Undergraduates of Higher Education in Shanghai. Third, the author would like to express sincere thanks to Professor Michael W. Schwartz, sponsor of my Research Scholar Program at St. Cloud State Universtiy, who gave me a lot of guidance and reviewed the whole paper.

\section{APPENDIX 1}

1.

2. experience

3. challenge

4. environment

5. courage
6. native

7. culture

8. familiar

9. consider

10. decision

\section{APPENDIX 2}

1. The challenge of living in a new environment can give you courage and self-confidence.

2. If you are thinking about where to study, consider all of these benefits and make a decision that is right for you.

\section{APPENDIX 3}

Working in the office and working from home both have advantages. In the office, you will have much contact with your colleagues. Daily contact with people at work is often how good friendships are made. Also, it can be very easy to concentrate on work in the office because there are very few opportunities to do private things. What's more, the working atmosphere helps one work enthusiastically and efficiently. On the other hand, there are also advantages of working from home. One of the major advantages is that you do not have to commute to work. Millions of people worldwide have to deal with rush-hour traffic to make their way to the office. Obviously, this is not necessary if you turn your home into your place of work. In addition, working at home gives you much more freedom to manage your working day. For example, if you work in an office, you are often asked to attend meetings, and your timetable is decided for you. This is not the case when you work in an office at home. So, if working in the office costs a lot, working from home will be the best replacement.

\section{APPENDIX 4}

1. Living in another country can be an exciting experience because everything seems new and different.

2. Another good reason to live abroad is to learn more about another culture.

3. On the other hand, there are also advantages of staying in your own country to study.

4. In your home country, you don't need to worry about taking classes in a foreign language.

5. If you stay in your own country, you can be close to your family and friends.

\section{APPENDIX 5}

\section{Online Shopping}

1. Online shopping is very convenient and saves a lot of time and energy.

2. Online shoppers can read a great many reviews about a commodity before committing to buy.

3. Online shopping can avoid facing the employees you are taking away from loved ones.

In-store Shopping

1. In-store shopping can help customers to confirm the quality of goods by watching, touching or smelling.

2. Shopping in stores is not only an experience of buying things but also a way to get relaxed from the stress in work and life.

3. In-store shopping is a good opportunity for family members to share their spare time and get much closer.

\section{APPENDIX 6}

Studying abroad and studying in your own country both have definite benefits for a student. Living in another country can be an exciting experience because everything seems new and different. The challenge of living in a new environment can give you courage and self-confidence, too. If you want to learn another language, living abroad is a great way to do that because you can read magazines or newspapers, watch television programs, or make friends with people who are native speakers. Another good reason to live abroad is to learn more about another culture. On the other hand, there are also advantages of staying in your own country to study. It is cheaper than living abroad, so you can save 
more money. Also, in your home country, everything is familiar. You don't need to worry about taking classes in a foreign language, and you can understand the culture and the expectations of teachers. Finally, if you stay in your own country, you can be close to your family and friends. So, if you are thinking about where to study, consider all of these benefits and make a decision that is right for you (Zemach, E. D. \& Rumisek, A. L., 2003).

\section{REFERENCES}

[1] Anderson, J. R. (1995). Cognitive psychology and its implications (4th ed.). New York, NY: Freeman.

[2] Brown, R. \& Richards, L. (2011). IELTS Advantage Writing Skills. London: Delta Publishing.

[3] Cai, J. (2014). The Adjustment of Policy on National Foreign Language Teaching in the Perspective of National Strategy. Foreign Language Education, 2, 40-44.

[4] Celce-Murcia, M., Brinton, M. D. \& Snow, A. M. (2014). Teaching English as a Second or Foreign Language (4th ed.). Boston: National Geographic Learning.

[5] Flower, L. \& Hayes, J. R. (1981). A Cognitive Process Theory of Writing. College Composition and Communication, 32 (4), 365-387.

[6] Fry, D. (1977). Homo loquens: Man as a talking animal. Cambridge: Cambridge University Press.

[7] Groome, D. (2014). An Introduction to Cognitive Psychology Processes and Disorders (3rd ed.). New York, NY: Psychology Press.

[8] Gu, Q. (1992). How to Improve CET Writing. Dongying: China University of Petroleum Press.

[9] Gu, Q. (2014). A Theoretical and Practical Study of the Listen-to-Write Approach. Shanghai: Shanghai Jiao Tong University Press.

[10] Gu, Q. \& Liu, J. (2016). The Listen-to-Write Approach to Improving CET Writing. Shanghai: Shanghai Jiao Tong University Press.

[11] Gui, S. (2000). A New Psycholinguistics. Shanghai: Shanghai Foreign Language Education Press.

[12] Hudmon, A. (2006). Learning and Memory. New York, NY: Infobase Publishing.

[13] Luo, J. \& Garner, M. (2017). The Challenges and Opportunities for English Teachers in Teaching ESP in China. Journal of Language Teaching and Research, 8(1), 81-86.

[14] Neisser, U. (1967). Cognitive Psychology. NewYork, NY: Appleton-Century-Crofts.

[15] Nunan, D. (2003). Practical English language teaching. New York, NY: McGraw-Hill.

[16] Zemach, E. D. \& Rumisek, A. L. (2003). College Writing from Paragraph to Essay. London: Macmillan Education.

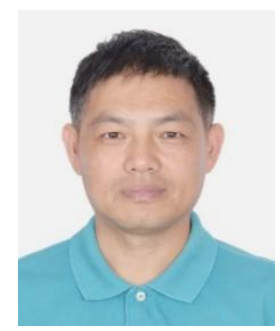

Qingsong Gu is an associate professor from School of Foreign Languages at Shanghai University of Engineering Science. He earned an MA degree in English from Shanghai Maritime University and has been teaching College English in China for more than 15 years. His research focuses on Teaching English as a Second or Foreign Language. Many years ago, he started to introduce listening in the classroom teaching of College English writing and in 2014, he first proposed LWA and gave a Chinese definition of it. Currently, he is a research scholar at St. Cloud State University, where he is conducting further research on LWA. 